\title{
TINGKAT PENGETAHUAN ORANG TUA DENGAN KEJADIAN NURSING BOTTLE CARIES
}

\author{
Diana Novita Sari ${ }^{1}$, Dewi Sodja Laela ${ }^{2}$, Sekar Restuning ${ }^{3}$ \\ ${ }^{1,2,3}$ Jurusan Keperawatan Gigi, Politeknik Kesehatan Kemenkes Bandung, Indonesia
}

\begin{tabular}{ll}
\hline Info Artikel & Abstrak \\
\hline Genesis Naskah: & $\begin{array}{l}\text { Pendahuluan: Karies gigi merupakan salah satu penyakit yang paling sering terjadi } \\
\text { padamasyarakat Indonesia, baik pada orang dewasa mau pun anak-anak. Karies dengan bentuk }\end{array}$ \\
$\begin{array}{l}\text { Submitted : 21 September 2020 } \\
\text { Revised : 8 Oktober 2020 }\end{array}$ & $\begin{array}{l}\text { yang khas dan paling sering terjadi pada anak dibawah } 5 \text { tahun sering kali disebut Nursing Bottle } \\
\text { Caries. Terjadinya Nursing Bottle Caries pada anak diakibatkan pola konsumsi susu formula } \\
\text { yang kurang tepat seperti cara penyajian menggunakan botol yang dihubungkan dengan lama }\end{array}$ \\
\hline Kata Kunci: & pemberian, frekuensi, waktu pemberian dan pengetahuan orang tua karena peran serta orang tua \\
Karies Gigi, Pengetahuan 2020 & sangat diperlukan. Tujuan: Penelitian ini bertujuan untuk mengetahui tingkat pengetahuan \\
Orang Tua, Nursing Bottle & orang tua dengan kejadian Nursing Bottle Caries di Perumahan Pangauban Silih Asih, Desa \\
Caries & $\begin{array}{l}\text { Pangauban, Kecamatan Batujajar, Kabupaten Bandung Barat. Metode: Jenis penelitian ini } \\
\text { adalah analitik dengan uji hipotesis menggunakan chi square. Sample diambil secara total }\end{array}$ \\
& $\begin{array}{l}\text { sampling dengan jumlah 30 responden. Hasil: Hasil uji chi sequare diperoleh hasil dengan } \\
\text { tingkat signifikan (0.000 < 0.05) Kesimpulan: Sehingga dapat disimpulkan bahwa terdapat }\end{array}$ \\
& hubungan bermakna antara tingkat pengetahuan orang tua dengan kejadian Nursing Bottle \\
& Caries di Perumahan Pangauban Silih Asih, Batujajar, Kabupaten Bandung Barat.
\end{tabular}

PARENTS KNOWLEDGE WITH THE INCIDENCE OF NURSING BOTTLE CARIES

\begin{abstract}
Keywords:
Dental Caries, Parents

Knowledge, Nursing Bottle

Caries.
\end{abstract}

\begin{abstract}
Background: Dental caries was one of the most common diseases in Indonesian society, both adults and children. Caries with a distinctive form and most often occurs in children under 5 years was often called Nursing Bottle Caries. Occurrence of Nursing Bottle Caries in children due to inadequate consumption patterns of formula milk such as how to used bottles that were connected with the duration of administration, frequency, time of administration and parents' knowledge. Purpose: This study aimed to determine the level of parental knowledge with the incidence of Nursing Bottle Caries in Pangauban Silih Asih Housing, Pangauban Village, Batujajar District, West Bandung Regency. Metode: This type of research was analytic with hypothesis testing using chi square. Samples were taken in total sampling with a total of 30 respondents. Result: Chi-square test results obtained with a significant level $(0.000<0.05)$ Conclusion: so it can be concluded that there was a relationship meaningful between the level of parental knowledge with nursing bottle caries in Pangauban Silih Asih Housing, Batujajar, West Bandung Regency.
\end{abstract}

\section{Korespondensi Penulis:}

Sekar Restuning

Jl. Lobunta Raya A.9 No.1 Cirebon

Email: sekar.reztu@gmail.com

(C) Jurusan Keperawatan Gigi Poltekkes Kemenkes Jakarta I Jl. Wijaya Kusuma No. 47-48 Cilandak Jakarta Selatan, Indonesia email: jdht@poltekkesjakarta1.ac.id 


\section{Pendahuluan}

Karies gigi merupakan salah satu penyakit yang paling sering dijumpai pada anak prasekolah (Purnama dkk, 2019). Karies gigi pada masa kanakkanak dapat mengganggu sistem pengunyahan dan mengganggu sistem pencernaan sehingga dapat memengaruhi perkembangan gigi anak dan kualitas hidup anak (Ngatemi, 2020).

Karies dengan bentuk yang khas dan paling sering terjadi pada anak dibawah 5 tahun disebut nursing bottle caries. Berdasarkan data yang dilakukan Adhani, nursing bottle caries tertinggi ada pada anak usia tiga tahun dengan penyebaran $76,6 \%$ (Adhani dkk, 2014). Terjadinya nursing bottle caries pada anak diakibatkan pola konsumsi susu formula yang kurang tepat seperti cara penyajian menggunakan botol yang dihubungkan dengan lama pemberian, frekuensi, dan waktu pemberian (Purwaningsih, 2016).

Data WHO tahun 2018 menggambarkan bahwa angka kejadian karies pada anak sekitar 60-90\% kasus. Berdasarkan hasil Riskesdas 2018, anak usia 3-5 tahun yang tinggal di pedesaan mengalami 95\% kejadian nursing bottle caries. Prevalensi nursing bottle caries di Indonesia pada tahun 2018 menunjukan peningkatan sebanyak $13,3 \%$ dari $81 \%$ menjadi 94,3\%, khususnya pada anak usia 3-5 tahun.

Faktor lain yang menyebabkan kejadian nursing bottle caries pada anak antara lain makanan, kebiasaan, dan kurangnya pengetahuan orang tua. Faktor tersebut dapat dijadikan acuan bagi orang tua untuk lebih memperhatikan makanan dan kebiasaan yang di berikan terhadap anaknya, supaya timbul kebiasaan anak dalam melakukan pembersihan gigi dan mulut secara teratur dan kebiasaan anak untuk makan-makanan yang sehat (Rompis dkk, 2016).

Penelitian yang dilakukan Pramita (2019) tentang hubungan tingkat pengetahuan orang tua tentang pemberian susu botol dengan kejadian nursing bottle caries pada anak usia 3-5 tahun di wilayah kerja Puskesmas Mengwi III Badung. Menunjukkan, jumlah anak usia 3-5 tahun yang mengalami nursing bottle caries yaitu 38 anak $(40,9 \%)$, dan anak yang tidak mengalami nursing bottle caries sebanyak 55 anak (59,1\%). Ditinjau dari karakteristik sebagian besar pada penelitian ini adalah anak usia 3 tahun yaitu sebanyak 55,9\% (52 anak), dan anak- anak tersebut diantaranya memiliki riwayat erupsi gigi pertama kali pada usia 8-12 bulan paling banyak yaitu 78,5\% (73 anak).

Penulis melakukan penelitian di Perumahan Pangauban Silih Asih, Desa Pangauban, Kecamatan Batujajar, Kabupaten Bandung Barat dikarenakan tempat tinggal yang lumayan jauh dari perkotaan sehingga kurangnya akses infomasi mengenai kesehatan gigi dan mulut.

\section{Metode}

Jenis penelitian yang akan digunakan adalah jenis peneliti analitik, dengan desain penelitian yang digunakan cross sectional. Pengambilan sampel dalam penelitian ini dilakukan dengan cara total sampling dengan alasan mengambil total sampling karena jumlah populasi yang kurang dari 100, sehingga sampel yang diambil oleh peneliti sebanyak 60 responden yang terdiri dari 30 orang tua dan 30 anak.

Penelitian ini dilaksanakan di Perumahan Pangauban Silih Asih, Desa Pangauban, Kecamatan Batujajar, Kabupaten Bandung Barat, mulai bulan Februari-Maret tahun 2020. Data yang digunakan adalah data primer yaitu pengetahuan orang tua diukur dengan kuesioner dan melakukan pemeriksaan gigi secara langsung untuk mengetahui kejadian Nursing Bottle Caries. Penelitian ini dianalisa menggunakan uji analisis berupa uji $C h i$ square. Chi square merupakan metode perhitungan statistika non parametik yang jenis datanya harus bersifat nominal.

\section{Hasil}

Hasil penelitian menunjukkan bahwa tingkat pengetahuan orang tua di Perumahan Pangauban Silih Asih Desa Pangauban Kecamatan Batujajar Kabupaten Bandung Barat termasuk kriteria kurang sebanyak 15 responden (50\%). Lebih jelasnya terdapat pada tabel 1 .

\begin{tabular}{ccc}
\hline Pengetahuan & Jumlah (n) & Persentase \% \\
\hline Baik & 7 & 23 \\
Cukup & 8 & 27 \\
Kurang & 15 & 50 \\
\hline Total & $\mathbf{3 0}$ & $\mathbf{1 0 0}$ \\
\hline
\end{tabular}

Tabel 1. Distrbusi Frekuensi Tingkat Pengetahuan Orang Tua 
Hasil penelitian tentang kejadian nursing bottle caries di Perumahan Pangauban Silih Asih Desa Pangauban Kecamatan Batujajar Kabupaten Bandung Barat Kriteria tinggi sebanyak 19 responden (63\%). Lebih jelasnya terdapat pada tabel 2.

Table 2. Distrbusi Frekuensi Kejadian Nursing Bottle Caries

\begin{tabular}{ccc}
\hline $\begin{array}{c}\text { Kejadian Nursing Bottle } \\
\text { Caries }\end{array}$ & $\begin{array}{c}\text { Jumlah } \\
\text { (n) }\end{array}$ & $\begin{array}{c}\text { Persentase } \\
\text { \% }\end{array}$ \\
\hline Rendah & 1 & 4 \\
Sedang & 3 & 10 \\
Tinggi & 19 & 63 \\
Sangat tinggi & 7 & 23 \\
\hline Total & $\mathbf{3 0}$ & $\mathbf{1 0 0}$ \\
\hline
\end{tabular}

Hasil penelitian menunjukkan hasil uji statistic Chi-square tingkat pengetahuan orang tua dengan kejadian nursing bottle caries dengan hasil signifikan $0,000<0,05$. Nilai Odds Ratio (OR) sebesar 10 menunjukan kecenderungan bahwa anak balita yang memiliki orang tua yang pengetahuannya kurang 10 kali lebih beresiko untuk mengalami kejadian nursing bottle caries dibanding anak yang memiliki orang tua berpengetahuan baik. Lebih jelasnya terdapat pada tabel 3 .

Tabel 3. Hasil Uji Statistik Hubungan Tingkat Pengetahua rang Tua dengan Kejadian Nursing Bottle Caries

\begin{tabular}{|c|c|c|c|c|c|}
\hline \multirow{2}{*}{ Pengetahuan } & \multicolumn{4}{|c|}{$\begin{array}{c}\text { Nursing Bottle } \\
\text { Caries }\end{array}$} & \multirow{2}{*}{ p-value } \\
\cline { 2 - 5 } & \multicolumn{2}{|c|}{ Ya } & \multicolumn{2}{|c|}{ Tidak } & \\
\cline { 2 - 5 } & $\mathrm{n}$ & $\%$ & $\mathrm{n}$ & $\%$ & \multirow{2}{*}{0} \\
\hline Baik & 5 & 71,4 & 2 & 28,6 & \multirow{2}{*}{0,000} \\
\hline Cukup & 5 & 62,5 & 3 & 37,5 & \\
\hline Kurang & 10 & 67 & 5 & 33 & \\
\hline Jumlah & 20 & 67 & 10 & 33 & \\
\hline
\end{tabular}

\section{Pembahasan}

Tabel 1 menunjukkan bahwa tingkat pengetahuan orang tua di Perumahan Pangauban Silih Asih Desa Pangauban Kecamatan Batujajar Kabupaten Bandung Barat dengan kriteria baik sebanyak 7 responden (23\%). Sehingga hasil tersebut menunjukkan bahwa pengetahuan ibu tentang nursing bottle caries dapat dikategorikan kurang dengan jumlah 15 responden. Karena sebagian besar dari responden tidak mengetahui pengetahuan nursing bottle caries. Hal ini disebabkan karena di wilayah tersebut minim sosialisasi terkait kesehatan gigi dan mulut. Begitu pun kondisi ekonominya tergolong menengah ke bawah, sebagian besar penduduknya bekerja sebagai supir, buruh pabrik dan lainnya. Sehingga kurangnya pengetahuan dan cara memelihara kesehatan gigi dan mulut anaknya.

Menurut teori dari (Erwana, 2013) sebagai seorang ibu seharusnya memiliki pengetahuan kesehatan gigi yang baik terutama dalam pemeliharaan kesehatan gigi anak dan pencegahan nursing bottle caries, pencegahan pada balita harus dilakukan secepatnya ketika gigi susu anak telah erupsi.

Tabel 2 menunjukan bahwa kebanyakan balita yang mengalami nursing bottle caries adalah balita yang kurang terjaga kebersihan gigi dan mulutnya karena seringkali menggunakan susu dalam dot dengan kriteria tinggi berjumlah 19 responden $(63 \%)$.

Karies adalah suatu penyakit infeksi yang dihasilkan dari interaksi bakteri. Karies gigi terjadi karena proses demineralisasi dari interaksi bakteri pada permukaan gigi. Bakteri bersifat asam sehingga dalam periode waktu tertentu, asam akan merusak email gigi dan menyebabkan gigi menjadi berlubang. Faktor etiologi terjadinya karies yaitu mikroorganisme plak, diet dan waktu (Mustika dkk, 2014).

Pemberian susu pada anak menjelang tidur, akan berisiko mengalami nursing bottle caries. Pada umumnya, gigi yang terkena kerusakan akibat nursing bottle caries adalah rahang atas bagian depan. Pada saat tidur, gigi-gigi rahang bawah akan tertutup lidah sehingga genangan air susu akan lebih menyerang gigi atas. Apabila kerusakan sudah mengenai jaringan di bawahnya maka akan berpengaruh terhadap pertumbuhan serta perkembangan gigi tetapnya kelak (Djamil, 2011). Selain akibat dari susu botol, saliva juga berpengaruh terhadap kebiasaan menggunakan susu botol dengan kejadian karies gigi pada anak karena Saliva merupakan sekresi air ludah yang sedikit atau tidak ada sama sekali memiliki presentase karies yang tinggi

Hasil penelitian dapat disimpulkan bahwa hasil uji statistic Chi-square tingkat pengetahuan orang tua 
dengan kejadian nursing bottle caries dengan hasil signifikan $0,000<0,05$ artinya pengetahuan orang tua berhubungan dengan kejadian nursing bottle caries. Penelitian ini sejalan dengan penelitian yang dilakukan oleh Jumriani (2019) membuktikan bahwa pengetahuan orang tua yang dalam kategori kurang paling banyak anaknya mengalami rampan karies. Hal ini disebabkan oleh karena kurangnya penyuluhan yang dilakukan oleh petugas kesehatan tentang kesehatan gigi dan mulut sehingga mnyebabkan rendahnya pengetahuan orang tua karena orang tua beranggapan gigi anak akan terganti setelah mengalami kerusakan, tetapi banyak orang tua tidak mengetahui dampak dari kerusakan gigi anak,yang akan menyebabkan anak susah makan, susah tidur karena giginya sakit.

Peran serta orang tua sangat diperlukan dalam membimbing, memberikan pengertian, mengingat dan menyediakan fasilitas kepada anak agar anak dapat memelihara kebersihan gigi dan mulutnya. Setiap manusia memiliki tingkat pengetahuan yang berbeda-beda. Tingkatan pengetahuan dimulai dari tahu (know), memahami (comprehension), aplikasi (application), analisis (analysis), sintesis (syntesis) dan evaluasi (evaluation). Semakin tinggi tingkat pengetahuan seseorang maka semakin tinggi pula kemampuan individu tersebut di dalam melakukan penilaian terhadap suatu materi atau objek. Penilaian tersebut inilah yang akan menjadi landasan seseorang untuk bertindak (Notoatmodjo, 2012). Diperkuat Purnama dkk (2020) menyatakan perilaku menyikat gigi dan tingkat kebersihan gigi anak sangat dipengaruhi oleh pendampingan orang tua. Pendapat lain juga Mariati (2015) bahwa pentingnya orang tua menjaga kebersihan gigi dan mulut anak agar terhindar dari rampan karies.

\section{Kesimpulan}

1. Tingkat pengetahuan orang tua tentang nursing bottle caries di Perumahan Pangauban Silih Asih, Desa Pangauban, Kecamatan Batujajar, Kabupaten Bandung Barat yang memiliki kriteria kurang ada $15(50 \%)$ responden.

2. Kejadian nursing bottle caries pada anak-anak di Perumahan Pangauban Silih Asih, Desa Pangauban, Kecamatan Batujajar, Kabupaten Bandung Barat mempunyai kriteria tinggi sebanyak $16(63 \%)$

3. Terdapat hubungan antara tingkat hubungan pengetahuan orang tua dengan kejadian nursing bottle caries.dengan hasil uji chi square signifikan $0,000<0,05$.

(C) Jurusan Keperawatan Gigi Poltekkes Kemenkes Jakarta I Jl. Wijaya Kusuma No. 47-48 Cilandak Jakarta Selatan, Indonesia email: jdht@poltekkesjakarta1.ac.id

\section{Saran}

Berdasarkan hasil penelitian yang telah dilakukan, penulis bermaksud memberikan saran:

1. Perlu adanya penyuluhan kepada orang tua mengenai Kesehatan Gigi dan Mulut khususnya kejadian Nursing Bottle Caries.

2. Perlunya kerja sama antara posyandu dengan tenaga Kesehatan setempat untuk mengadakan UKGM (Usaha Kesehatan Gigi Masyarakat) agar status Kesehatan pada balita menjadi lebih baik.

\section{Daftar Pustaka}

Adhani R, Sari HV, Aspriyanto D (2014). Nursing Mouth Caries Anak 2-5 tahun di Puskesmas Cempaka Banjarmasin. Jurnal PDGI: Vol. 63 No. 1

Kementerian Kesehatan Republik Indonesia (2018). Riset Kesehatan Dasar. Badan Penelitian dan Pengembangan, Jakarta.

Djamil MS (2011). A-Z: Kesehatan Gigi: Panduan Lengkap Kesehatan Gigi Keluarga. Peneribit: Tiga Serangkai, Solo.

Erwana AF (2013). Seputar Kesehatan Gigi dan Mulut. Penerbit: Rapha, Yogyakarta.

Jumriani (2019) Gambaran Pengetahuan Orang Tua Terhadap Kejadian Rampan Karies Pada Siswa Di TK Karya Kota Makassar. Media Kesehatan Gigi: Vol. 18 No. 1 Tahun 2019

Mariati WN (2015). Pencegahan Dan Perawatan Karies Rampan. Jurnal Biomedik (JBM): Volume 7, Nomor 1, Maret 2015, hlm. 23-28

Mustika MD, Amy NC, Cholil (2014). Insidensi Karies Gigi Pada Anak Usia Prasekolah Di Tk Merah Mandiangin Martapura Periode 20122013. Dentino Jurnal Kedokteran Gigi: Vol II. No 2. September 2014

Ngatemi, Purnama T. (2020). Dental Health Handbook as Parents Monitoring in the Formation of Independence for Brushing Teeth in Early Childhood. Indian Journal of Public Health Research Development, 11(1):785-790.

Notoatmodjo S (2012). Promosi Kesehatan: Sebuah Pengantar Proses Belajar Mengajar dalam Pendidikan. Penerbit: Rineka Cipta, Jakarta.

Pramita D (2019). Prevalensi bottle feeding caries dan Faktor Risiko pada Anak Usia 3 sampai 5 Tahun di Wilayah Kerja Puskesmas Mengwi III Bandung. Dental Jurnal: Vol.03 No.1

Purnama T, Rasipin R, Santoso B. (2019). Pengaruh Pelatihan Tedi's Behavior Change Model pada Guru dan Orang Tua terhadap Keterampilan 
Menggosok Gigi Anak Prasekolah. Jurnal Quality Kesehatan. 13(2):75-81.

Purnama T, Rasipin R, Ngatemi. (2020). Tedi's Behavior Change Model to Improving Brushing Teeth Behavior Parents. Journal of Applied Health Management and Technology. 2(1):1-12

Purwaningish A (2016). Pengaruh Pemberian Susu

Formula Menggunakan Botol Susu (Dot) Terhadap Kejadian Rampan Karies Pada Anak Prasekolah Di Kelurahan Pabelan. Naskah Publikasi. Fakultas Ilmu Kesehatan Universitas Muhammadiyah Surakarta

Rompis C, Damajanty P, Paulina G (2016). Hubungan Tingkat Pengetahuan Ibu Tentang Kesehatan Gigi Anak Dengan Tingkat Keparahan Karies Anak TK di Kota Tahuna. Jurnal e-GiGi: Volume 4 Nomor 1, JanuariJuni 2016 